\title{
Canadian surgeon and resident involvement in international plastic surgery
}

Yvonne Ying, MD, MSc, MEd

Claudia Malic, MD

Accepted Sept. 12, 2020

\section{Correspondence to:}

Y. Ying

Department of Surgery

CHEO

401 Smyth Road, Rm 3363

Ottawa ON K1H 8L1

yying@cheo.on.ca

DOI: $10.1503 /$ cjs.008720

\section{SUMmARY}

Surgery has become increasingly recognized as an important component of health care in low and middle income countries (LMICs). Many surgeons from high income countries (HICs) are interested in working on improving access to surgery in LMICs. We sought to evaluate the involvement and potential barriers of Canadian plastic surgeons and plastic surgery residents in international work with an online survey. The survey indicated that plastic surgery residents have a high interest and involvement in international electives, with $45 \%$ of graduating residents previously involved. About $40 \%$ of respondents were involved in international projects, and academic plastic surgeons were more frequently involved than community surgeons. Taking time off work and personal/family commitments were cited as the greatest obstacles for those who are currently involved, whereas finding opportunities was the biggest challenge for those who would like to participate in the future. urgery has become increasingly recognized as an important component of health care in low and middle income countries (LMICs). There are many international collaborative projects building surgical capacity, including collaborations with Canadian surgeons. Many Canadian surgeons are involved in teaching, research and providing clinical care in LMICs where surgical care is unaffordable and inaccessible for many. There is also increasing interest in international surgery among surgical residents in high income countries (HICs), with more than $85 \%$ of surgical trainees interested in incorporating international surgery into their future practice. ${ }^{1}$ But do these intentions turn into actual involvement?

The field of plastic surgery has a long history of involvement in international surgery initiatives, but we have no real understanding of the degree of involvement among plastic surgeons. We sought to determine how Canadian plastic surgeons are involved in international work, and whether these opportunities are available to plastic surgery residents. An email survey was sent to all 411 members of the Canadian Society of Plastic Surgeons, with a single follow-up email to nonresponders. Questions revolved around international surgery projects, and could include clinical, educational, or research projects. There were 173 responses (42\%), of which 119 were from practising surgeons, 42 were from residents in Canadian training programs, and the rest were from clinical fellows and elective residents. Responses came from across the country, and the time in practice and level of training varied among respondents (Table 1 and Table 2).

The survey showed a high participation rate in international surgery initiatives among Canadian plastic surgery residents, with $21 \%$ of trainees having participated in an international project and an additional $38 \%$ planning to do so later in their residency. Most trainees participated in their fourth year of residency, leading to participation rates of $45 \%$ by the final year of training. This compared with $27 \%$ of staff surgeons who had participated when they were residents. Participation in international opportunities 


\begin{tabular}{l} 
Table 1. Demographic characteristics of staff surgeons \\
$(\boldsymbol{n}=119)$ \\
\begin{tabular}{|lc|}
\hline Characteristic & No. $(\%)$ \\
\hline Practice type & $56(47)$ \\
\hline Community & $63(53)$ \\
\hline Academic & \\
\hline Location of practice & $56(47)$ \\
\hline Ontario & $14(12)$ \\
\hline Quebec & $13(11)$ \\
\hline Alberta & $4(3)$ \\
\hline Manitoba/Saskatchewan & $10(8)$ \\
\hline Atlantic Canada & $20(17)$ \\
\hline British Columbia & $2(2)$ \\
\hline Outside Canada & \\
\hline Years in practice & $29(24)$ \\
\hline$<5$ & $24(20)$ \\
\hline $5-9$ & $15(13)$ \\
\hline $10-14$ & $6(5)$ \\
\hline $15-19$ & $45(38)$ \\
\hline$\geq 20$ &
\end{tabular} \\
\hline
\end{tabular}

Table 2. Demographic characteristics of residents ( $n=42)$

\begin{tabular}{|lc|}
\hline Characteristic & No. $(\%)$ \\
\hline Postgraduate year of training & $7(17)$ \\
\hline 1 & $7(17)$ \\
\hline 2 & $10(24)$ \\
\hline 3 & $7(17)$ \\
\hline 4 & $11(26)$ \\
\hline 5 & \\
\hline Province of training & $21(50)$ \\
\hline Ontario & $10(24)$ \\
\hline Quebec & $4(10)$ \\
\hline Alberta & $3(7)$ \\
\hline Manitoba & $2(5)$ \\
\hline Atlantic Canada & $2(5)$ \\
\hline British Columbia & \\
\hline
\end{tabular}

Table 3. Challenges for residents and staff who participated in international surgical projects*

\begin{tabular}{|lcc|}
\hline \multirow{2}{*}{ Challenge } & \multicolumn{2}{c|}{ No. (\%) } \\
\cline { 2 - 3 } & Residents, $n=9$ & Staff, $n=49$ \\
\hline Finances & $3(33)$ & $13(27)$ \\
\hline Inability to take time off & $3(33)$ & $37(76)$ \\
\hline Personal or family commitments & $2(22)$ & $30(61)$ \\
\hline Finding opportunities & $1(11)$ & $11(22)$ \\
\hline No significant challenges & $5(56)$ & $1(2)$ \\
\hline *Respondents were able to choose more than one response. \\
\hline
\end{tabular}

appears much higher among Canadian plastic surgery residents than residents in other surgical specialties; for example, only $5 \%$ of Canadian orthopedic and general surgery trainees reported international involvement in a 2011 study. $^{2}$ Rates also appear to have increased over time, with current trainees participating more than those currently in practice.
Table 4. Factors that prevented residents and staff from participating in international surgery projects

\begin{tabular}{|lcc|} 
& \multicolumn{2}{c|}{ No. (\%) } \\
\cline { 2 - 3 } Factor & Residents, $n=33$ & Staff, $n=70$ \\
\hline Reason unable to participate* & & $14(26)$ \\
\hline Finances & $4(13)$ & $29(54)$ \\
\hline Inability to take time off & $13(41)$ & N/A \\
\hline Opportunity did not present itself & $15(47)$ & \\
\hline$\quad$ Plans to participate later in residency & $16(50)$ & $54(77)$ \\
\hline Interested in participating in future & $16(23)$ \\
\hline Yes & $31(97)$ \\
\hline No & $2(3)$ \\
\hline $\begin{array}{l}\text { N/a }=\text { not applicable. } \\
\text { *Respondents were able to choose more than one response. }\end{array}$ \\
\hline
\end{tabular}

Previous studies have cited taking time off and finances as the greatest challenges to participating in international projects, and this is still true for the trainees who responded to our survey (Table 3). However, $56 \%$ of trainees who had been involved reported they did not have any significant challenges in participating. It is unclear whether their training program provided funding, but some training programs in Canada allow residents to participate in international projects as part of their training, perhaps mitigating the challenges of taking time off. Residents can gain many CanMEDS competencies from participating in international electives, and residency programs can justify including international rotations as part of their training programs. ${ }^{3,4}$ By allowing an international experience to be included as part of training, one of the biggest obstacles to participation can be eliminated. All Canadian surgical training programs can work to make these opportunities more accessible, and plastic surgery programs in Canada have shown that it is possible to have high participation rates in international surgery among trainees.

Most trainees who did not participate (97\%) reported that they would like such an opportunity and that the greatest challenge was finding opportunities to do so. Surgeons could work with partner LMICs to develop more mutually beneficial opportunities. For example, by their fourth year in training, many HIC surgical residents are involved in teaching surgical skills to medical students and junior residents and could therefore help with shortage of surgeons available in LMICs for teaching due to high clinical workloads. We can work toward finding more opportunities for residents to participate so that they can build connections for future continued involvement.

Among practising plastic surgeons, more than $40 \%$ had been involved in some international surgery project since beginning practice. There are no data available to compare this rate of involvement to that of other surgical specialists in Canada. However, these data show that many who had intended to participate in international 
work after graduation did not do so. The most commonly cited obstacle among those who had not participated in international work was finding the opportunities to contribute (77\%; Table 4).

For those who were involved in international work, two-thirds participated at least once every 2 years; they cited taking time off work and personal/family commitments as the greatest challenges (Table 3). This seems to imply that there are opportunities for these surgeons to be more involved, but they are limited by other commitments. At the same time, some surgeons are interested in volunteering, but do not know where to find these opportunities. We could therefore do a better job helping international partners recruit Canadian surgeons especially community surgeons, who were significantly less involved than academic surgeons in international projects $(27 \%$ v. $54 \%)$. It is difficult to be certain of the cause of this difference; it may be that involvement in international surgery is perceived as more of an academic endeavour, or that academic surgeons may have more connections for partnerships and opportunities. ${ }^{5}$ Notably, community surgeons often have a much broader scope of practice than academic surgeons, which may make their experience more applicable in low-resource situations where there are not many subspecialists. Improved collaborations may be beneficial for both academic and community surgeons, and most importantly for their partners in LMICs, who may be looking for staffing support.

\section{Conclusion}

Our survey has given us a better understanding of the current landscape of Canadian involvement in international plastic surgery initiatives. With a $42 \%$ response rate, it shows a good picture of Canadian plastic surgeons, but may still have a bias toward those who have an interest in international work. The survey responses show high interest among our trainees, and that a relatively high number are able to participate. However, many who are interested in volunteering are still unable to do so because of lack of opportunities. Improving partnerships and expanding involvement and recruitment across Canada to community surgeons can help to tap this resource in a mutually beneficial way. Residency programs can also consider how to incorporate international electives within the training program to improve access to learning opportunities, while simultaneously helping to build surgical capacity around the world.

Affiliations: From CHEO, Ottawa, Ont.; and the Department of Surgery, University of Ottawa, Ottawa, Ont.

Competing interests: None declared.

Contributors: Both authors contributed substantially to the conception, writing and revision of this article and approved the final version for publication.
Content licence: This is an Open Access article distributed in accordance with the terms of the Creative Commons Attribution (CC BYNC-ND 4.0) licence, which permits use, distribution and reproduction in any medium, provided that the original publication is properly cited, the use is noncommercial (i.e., research or educational use), and no modifications or adaptations are made. See: https://creativecommons. org/licenses/by-nc-nd/4.0/

\section{References}

1. Powell AC, Casey K, Liewehr DJ, et al. Results of a national survey of surgical resident interest in international experience, electives, and volunteerism. 7 Am Coll Surg 2009;208:304-12.

2. Matar WY, Trottier DC, Balaa F, et al. Surgical residency training and international volunteerism: a national survey of residents from 2 surgical specialties. Can J Surg 2012;55:S191-199.

3. White CP, Lecours C, Bortoluzzi P, et al. International plastic surgery missions: a framework for resident education using the CanMEDS competencies. Ann Plast Surg 2013;71:324-7.

4. Goecke ME, Kanashiro J, Kyamanywa P, et al. Using CanMEDS to guide international health electives: an enriching experience in Uganda defined for a Canadian surgery resident. Can 7 Surg 2008;51:289-95.

5. Ying Y, Rekman J, McCarthy A. International surgery: How to be involved while maintaining a surgical practice. Am 7 Surg 2019;218:71-6. 